\title{
A INTERDISCIPLINARIDADE EM CTS: UM ESTUDO DA PRODUÇÃO CIENTIIFICA VOLTADA PARA O ENSINO DE CIÊNCIAS COM ANÁLISE BIBLIOMÉTRICA E DE REDES
}

\section{LÍVIA DA FRAGA LIMA}

Cefet-RJ

E-mail: liviafrh@yahoo.com.br

\section{ARMANDO GIL FERREIRA DOS SANTOS}

Cefet-RJ

E-mail: gilarm@gmail.com

\section{LUIZ NEY D'ESCOFFIER}

\section{Cefet-RJ}

Fiocruz

E-mail: lescof@gmail.com

\section{TAÍS CONCEIÇÃO DOS SANTOS}

\section{Cefet-RJ}

E-mail: taisquim@hotmail.com

\section{ÁLVARO CHRISPINO}

\section{Cefet-RJ}

E-mail: alvaro.chispino@gmail.com

\section{RESUMO:}

O presente trabalho apresenta o estado da arte da produção científica nacional sobre interdisciplinaridade e contextualização, no universo da produção do enfoque Ciência, Tecnologia e Sociedade (CTS), voltada para o ensino de ciências. A metodologia utilizada foi a análise bibliométrica e de redes de 28 artigos selecionados a partir dos 244 artigos que compõem o Banco de Dados do Grupo CTS e Educação do CEFET/RJ, catalogados no período de 1996 a 2016. As análises foram discutidas a partir de categorias, a saber: distribuição de artigos por ano; por revista; por instituição; por autores; por área e grau de formação dos autores; por autores, trabalhos e idiomas mais citados, enquanto que as redes foram discutidas a partir das seguintes categorias de análises: redes de coautoria, redes de instituições e redes de palavras-chave. Concluiu-se que as noções de contextualização e interdisciplinaridade são discutidas nos artigos sem sua devida conceituação, na perspectiva de que a utilização do contexto pode ser o elemento facilitador no processo de ensino-aprendizagem, enquanto a prática interdisciplinar consiste em 
prática pedagógica ampla que reconhece a necessidade de rompimento de barreiras entre as disciplinas escolares, promovendo a dinâmica interativa no ensino dessas diferentes disciplinas. Foi possível verificar ainda que a produção científica voltada para a interdisciplinaridade em CTS é escassa, onde os primeiros artigos datam de 2001, e que as instituições e grupos de autores possuem pouca interação entre si.

\section{PALAVRAS-CHAVE:}

CTS. ensino de ciências. interdisciplinaridade. contextualização. redes sociais.

THE INTERDISCIPLINARITY IN CTS: A STUDY OF THE SCIENTIFIC PRODUCTION RETURNED TO THE TEACHING OF SCIENCES WITH BIBLIOMETRIC AND NETWORKS ANALYSIS

\section{ABSTRACT:}

This paper presents the state of the art of national scientific production, about interdisciplinarity and contextualization, in the universe of production of the Science, Technology and Society (STS) approach, focused on science education. The methodology used was the bibliometric and network analysis of 28 articles selected from the 244 articles that make up the Database of the CEFET/RJ CTS Group and Education, cataloged from 1996 to 2016. The bibliometric analysis is discussed from categories, namely: distribution of articles per year; by magazine; per institution; by authors; by area and degree of training of the authors; by most cited authors, works and languages. Networks are analyzed from categories of analysis, namely: co-authoring networks, institutional networks and keyword networks. It is concluded that the notion of contextualization and interdisciplinarity are discussed in the articles, without their due conceptualization, in the perspective that the use of context can be the facilitating element in the process of teaching-learning, while the interdisciplinary practice consists of broad pedagogical practice that recognizes the need to break down barriers between school disciplines, promoting interactive dynamics in the teaching of these different disciplines. The scientific production focused on interdisciplinarity in STS is scarce, where the first articles date from 2001. The institutions and groups of authors have little interaction with each other.

\section{KEYWORDS:}

STS. science teaching. interdisciplinarity. contextualization. social networks.

\section{INTRODUÇÃO}

[...] o papel específico da atividade interdisciplinar consiste, primordialmente, em lançar uma ponte para ligar as fronteiras que haviam sido estabelecidas anteriormente entre as disciplinas com o objetivo preciso de assegurar a cada uma seu caráter propriamente positivo, segundo modos particulares e com resultados específicos. (H. Japiassú, 1976) 
A produção científica determina o estado de arte de sua área. A análise dessa produção com métodos estatísticos e matemáticos permite construir indicadores sobre a dinâmica e evolução da informação científica e tecnológica da área do conhecimento em estudo, o que, de acordo com as áreas de Ciência da Informação e Biblioteconomia, é denominado de análise bibliométrica ou bibliometria.

O precursor do estudo de redes sociais é o antropólogo John Arundel Barnes e, inclusive, atribui-se ao mesmo a cunhagem do termo social network em seu trabalho intitulado Class and Committee in a Norwegian Island, publicado na revista Human Relations, em 1954. Neste artigo, Barnes (1954) afirma que uma rede social é um campo social em que se praticam relações e intercâmbios de diferentes tipos entre indivíduos. Assim, a Análise de Redes Sociais (ARS) permite representar as redes sociais através de dois elementos: nós (atores da rede) e ligações possíveis entre eles (relações entre os atores que compõem a rede).

A área de Ciência, Tecnologia e Sociedade (CTS) é hoje uma área em expansão, ou seja, trata-se de uma área que está em construção. Segundo Cutcliffe (2003), CTS surgiu nos Estados Unidos, na década de 1960, como um campo acadêmico explícito de ensino e investigação, diante da necessidade de uma compreensão mais completa do contexto social da ciência e da tecnologia, em um período em que estudiosos e críticos mais ativistas levantaram dúvidas sobre o caráter benéfico da ciência e tecnologia que, logo após a Segunda Guerra Mundial, constituía um consenso. Dessa maneira, a cultura tecnológica imposta pelas novas descobertas científicas no período pós-guerra era questionada e eram provocadas reflexões sobre os efeitos nocivos decorrentes dessa época (TRÓPIA; AMORIM; MARTINS, 2008). O enfoque inicial dos estudos CTS era quase sempre dirigido à educação dos estudantes de ciências e de engenharia para mostrar-Ihes o verdadeiro impacto social de seu trabalho, considerado por Cutcliffe (2003) como a primeira geração de 
trabalhos voltados para a temática CTS. Ainda segundo o referido autor, os primeiros cursos e programas curriculares de CTS surgiram em instituições e faculdade de engenharia. Mais tarde, os estudantes de humanidades se interessaram por essas questões e, de forma muito rápida, surgiu a segunda geração de trabalhos de cursos de CTS e que tomou como base a interpretação da ciência e tecnologia como processos sociais (CUTCLIFFE, 2003).

Segundo Chrispino (2008), as distorções da imagem da Ciência e da Tecnologia, apresentadas por Cachapuz Et al (2005), servem para explicar a dificuldade de se transmitir o conhecimento científico de forma crítica, objetivando a melhor formação do cidadão que se aproprie dos conhecimentos a fim de interagir da melhor maneira possível com o meio social. São elas: visão descontextualizada, visão elitista e individualista, visão empiro-indutivista e ateórica, visão rígida e infalível e, por último, visão aproblemática e a-histórica.

Sendo assim, o estudo da produção científica dessa área nos permite contribuir para o seu conhecimento, crescimento e desenvolvimento. Vale ressaltar que, por ser uma área em crescimento e em desenvolvimento, há muito debate, porém, existe pouco consenso entre a comunidade CTS, segundo Membiela (2001). Alguns autores abordam CTS como sendo uma metodologia, outros como sendo uma abordagem curricular, outros ainda como sendo uma cultura. O que diferencia tais abordagens é a perspectiva de análise, os objetivos pretendidos, o local de onde fala o autor e a família de conhecimento a que se filia o autor.

Devido à falta de concordância entre os autores a respeito do que seja CTS, decidimos adotar a interpretação utilizada por Cutcliffe (2003), como sendo uma abordagem para a "interpretação da ciência e da tecnologia como um processo social", e complementamos a partir de Chrispino (2017), construída a partir dos aspectos educacionais. 
Visto que a interdisciplinaridade é algo inerente à área de CTS, uma vez que pesquisadores com diversas formações se dedicam sobre os estudos de CTS voltados para sua área de atuação, a questão que surge é saber como a interdisciplinaridade e contextualização se apresentam no âmbito da abordagem CTS. Dessa forma, este artigo tem como objetivo investigar como tais conceitos se relacionam com os estudos em CTS, identificando seus pontos de aproximação e convergência e explorando, por meio de análise bibliométrica e de redes, a produção científica da área, realizando coleta de dados no Banco de Dados do Grupo CTS e Educação, do CEFET/RJ, Brasil. Salienta-se que o referido banco de dados também foi utilizado no trabalho de Rocha Et al. (2017), o qual apresentou um estudo similar voltado para os estudos em CTS, abordando a análise de redes, porém, voltada para outra temática: o ensino de Biologia.

\subsection{INTERDISCIPLINARIDADE E CONTEXTUALIZAÇÃO}

Partimos da ideia de que o conceito de interdisciplinaridade não é uma nova proposta pedagógica (POMBO, 1993). A interdisciplinaridade, segundo a autora, emerge do próprio ambiente escolar, proveniente do ideário dos próprios professores e não como uma apresentação pedagógica inovadora.

Mas o que significa interdisciplinaridade? Trata-se de alguma transferência de métodos entre os componentes curriculares de uma determinada série ou ano escolares? A partir da perspectiva de Pombo (1993) não há ainda uma teoria definida a respeito da interdisciplinaridade. Entretanto, cabe aqui descrever algumas compreensões preliminares, sob o ponto de vista histórico, que se desdobrou em discussões e pesquisas por três décadas: 70, 80 e 90.

Segundo a autora Fazenda (2008), os estudos iniciais a respeito da interdisciplinaridade foram: 
$\rightarrow 1970$ - construção epistemológica da interdisciplinaridade, em busca de uma explicitação filosófica, procurava a definição de interdisciplinaridade.

$\rightarrow 1980$ - explicitação das contradições epistemológicas decorrentes dessa construção, em busca de uma diretriz sociológica, tentar explicitar um método para a interdisciplinaridade.

$\rightarrow 1990$ - construir uma nova epistemologia, a própria da interdisciplinaridade, em busca de um projeto antropológico, construção de uma teoria da interdisciplinaridade. (FAZENDA, 2008, p. 17-18)

Fazenda (1999) afirma que o movimento surgiu na França e na Itália, em meados da década de 1960, época em que os movimentos estudantis reivindicavam um novo estatuto de universidade e escola, como tentativa de elucidação e de classificação temática das propostas educacionais que começavam a aparecer na Europa.

No Brasil, a interdisciplinaridade chegou ao final dos anos sessenta e, conforme Fazenda (1999), com sérias distorções, como um modismo, uma palavra de ordem a ser explorada, usada e consumida por aqueles que se lançam ao novo sem avaliação.

No início da década de 1970, a preocupação fundamental era a de uma explicitação terminológica e a primeira produção significativa sobre a interdisciplinaridade no Brasil é de Hilton Japiassú que, na época, já apresentava os principais questionamentos a respeito da temática e seus conceitos, fazendo uma reflexão sobre as estratégias interdisciplinares, baseada em experiências realizadas naquele período.

Diversos autores da literatura especializada, como Piaget, Japiassú e Palmade apresentam definições superficiais a respeito da interdisciplinaridade, desde a colaboração de disciplinas, que se permeia e se integra, até ao rompimento das barreiras disciplinares que se configuram em uma ideia, por si só, absoluta. 
Pombo (1993) menciona que alguns exemplos da literatura especializada podem apontar para a diversidade de ideias e definições do vocábulo interdisciplinaridade. Como exemplos, a autora ressalta:

Piaget (1972), a interdisciplinaridade aparece como "intercâmbio mútuo e integração recíproca entre várias disciplinas (...tendo) como resultado um enriquecimento recíproco".

Japiassú (1976), afirma que: "a interdisciplinaridade caracteriza-se pela intensidade das trocas entre os especialistas e pelo grau de interação real das disciplinas no interior de um mesmo projeto de pesquisa".

Palmade (1979) vai além, propondo que a interdisciplinaridade se perceba como: "a integração interna e conceitual que rompe a estrutura de cada disciplina para construir uma axiomática nova e comum a todas elas, como fim de dar uma visão unitária de um setor do saber". (POMBO, 1993, p. 10).

Apesar de inúmeros enfoques concedidos ao termo interdisciplinaridade, por diversos teóricos, a compreensão parece ser comum a todos. Entretanto, essa compreensão existente está na necessidade de integrar os significados na construção desses saberes e perceber que eles se relacionam nesse conjunto de ideias.

Outras relações disciplinares, como a pluridisciplinaridade e transdisciplinaridade, podem ser demonstradas (Pombo, 1993). Entretanto, iremos nos concentrar na interdisciplinaridade por acharmos este um conceito mais geral que melhor define nossa intenção neste artigo.

Desta maneira, é importante dialogarmos com as bases teóricas que apresentam as ideias e defesas a respeito da interdisciplinaridade. Destacamos o entendimento do conceito de interdisciplinaridade, segundo Japiassú (2006), em uma perspectiva que permite alcançar novas compreensões a partir da integração dos saberes: 
A pesquisa interdisciplinar é a que se realiza nas fronteiras e pontos de contato entre diversas ciências (por exemplo, entre a psicanálise e sociologia, entre psiquiatria e psicologia) podendo ser obra tanto de um indivíduo quanto de uma equipe. Geralmente culmina na produção por fusão, de uma nova disciplina interdisciplinar (a biofísica). A pesquisa interdisciplinar não se contenta em promover a convergência e a complementaridade de várias disciplinas para atingir um objetivo comum; busca utilizar essa colocação em presença para tentar obter uma síntese entre os métodos utilizados, as leis formuladas e as aplicações propostas. (JAPIASSÚ, 2006, p. 38-39).

Analisamos a revelação do conceito de interdisciplinaridade, segundo o autor, como um alerta às instituições de ensino, que ainda sustentam um sistema cujos componentes curriculares não têm mobilidade para lidar com as concepções mais complexas de integração do saber. De fato, vivenciamos dessa forma, no cotidiano escolar, esse modelo resistente e ainda preso a métodos rigorosos de ensino.

Como já foi descrito anteriormente, basta que a prática de ensino integrado, de alguma forma, supere o mínimo possível do processo contínuo para que a proposta da interdisciplinaridade se faça presente e seja defendida. Todavia, o cenário que encontramos nas escolas, reforça cada vez mais os problemas e as dificuldades para o trabalho docente em parceria, integrado e com experiências interdisciplinares.

A contextualização trata-se de uma forma de apresentar os conteúdos escolares tendo em vista a utilização do contexto como elemento facilitador no processo de ensino-aprendizagem, tornando tal processo mais significativo para os estudantes. Em outras palavras, é uma possibilidade de aproximação e articulação dos conteúdos escolares com a realidade do estudante, como mencionam Macedo e Silva (2014), a partir da análise de diversos artigos, documentos oficiais, teses e dissertações. 
Segundo Kato (2007, p. 13, grifo do autor):

[...] o termo 'contextualização' é uma derivação do termo 'contexto' que vem do latim contextu e pode ser entendido por um encadeamento de idéias de um texto, ou seja, a forma como estão ligadas entre si as diferentes partes de um todo organizado. [...] os significados de 'contexto' variam de contexto para contexto, ou seja, não há um único significado, tampouco, um único contexto de significância. Consequentemente inferese que a ação relacionada ao 'contexto', isto é, a 'contextualização' pode trazer, também, significados múltiplos. No entanto, o que nos interessa são as concepções de contextualização no campo educacional, mais precisamente no ensino de ciências. É preciso reconhecer as concepções dessa noção para identificar em que sentido se busca utilizá-la no contexto de ciências.

Kato (2007) afirma que o termo "contextualizar" pode também significar situar ou relacionar partes a um todo, pois vem do termo "contexto", que significa conjunto, todo, totalidade.

A Lei de Diretrizes e Bases da Educação (LDB no 9.394/96), ao propor a reforma do ensino médio, colocou em pauta a ideia da contextualização a ser trabalhada e articulada nas escolas a partir do contexto histórico, econômico, social, ambiental e cultural dos estudantes, acreditando na compreensão dos conhecimentos para uso cotidiano. A referida lei estabelece que os arranjos curriculares devam ser oferecidos conforme a relevância para o contexto local. É preciso considerar ainda que os PCNs, criados pelo Ministério da Educação (MEC), estão estruturados sobre os eixos de interdisciplinaridade e contextualização que constitui os seus dois eixos principais, visando tratar os conteúdos de modo interdisciplinar e buscando integrar o cotidiano social com o saber escolar (BRASIL, 2006). Sendo assim, de acordo com os PCNs e os PCNEMs, a abordagem interdisciplinar dos conteúdos complementa a contextualização e juntas constituem possibilidade de ação pedagógica a ser desenvolvida. Voltando-se para a educação 
CTS e a abordagem interdisciplinar e contextualizada no ensino, Strieder (2016) analisa os diferentes documentos oficiais voltados à educação científica e ao ensino médio e conclui que a educação CTS possui respaldo em tais documentos, ainda que em abordagens pouco críticas.

Dessa forma, Lopes (2002, p. 390), ao analisar o conceito de contextualização presente nos PCNEMs e a submissão destes ao mundo produtivo, afirma que "o conceito de contextualização foi desenvolvido pelo MEC por apropriação de múltiplos discursos curriculares, nacionais e internacionais, oriundos de contextos acadêmicos, oficiais e das agências multilaterais". Tal conceito, conforme consta no documento oficial, se fundamenta na ideia de David Stein sobre uma aprendizagem situada, com base na vivência de situações do dia-a-dia, de acordo com os interesses dos estudantes, e no desenvolvimento de atividades desvinculadas da pura transmissão de conceitos (BRASIL, 1999).

\section{METODOLOGIA}

O propósito deste trabalho foi avaliar como estão representados e como se relacionam os temas interdisciplinaridade e contextualização nas publicações de ensino CTS. Para isso, foi consultado o Banco de Dados do Grupo CTS e Educação, do CEFET/RJ, Brasil. Este banco é composto por 244 artigos e foi criado a partir da busca das palavras "ciência", "tecnologia" e "sociedade", juntas ou separadas, nos campos "resumo", "palavras-chave" ou "título". Assim, constitui-se de informações referentes a toda a produção brasileira publicada em 31 revistas eletrônicas indexadas pelo Qualis na área de ensino, entre os anos de 1996 a 2016, que representam a área CTS no ensino no Brasil neste período.

As revistas contempladas no Banco de Dados são: Acta Scientiae; Alexandria: Revista de Educação em Ciência e Tecnologia; Avaliação; Biodiversidade; Caderno 
Brasileiro de Ensino de Física; Ciência \& Cognição; Ciência \& Educação; Ciência e Ensino; Ciência em Tela; Ciências e Ideias; Debates em Educação Científica e Tecnológica; Educação Matemática Pesquisa; Educar em Revista; Ensaio: pesquisa em educação em ciências; Ensino de Ciências e Tecnologia em Revista; Ensino, Saúde e Ambiente; Experiências em Ensino de Ciências; Investigações em Ensino de Ciências; Pesquisa em Educação Ambiental; Química Nova na Escola; Química Nova; Revista Brasileira de Ciência, Tecnologia e Sociedade; Revista Brasileira de Ensino de Ciência e Tecnologia; Revista Brasileira de Ensino de Física; Revista de Ensino de Ciências e Engenharia; Revista de Ensino de Ciências e Matemática - RENCIMA; Revista de Ensino de Engenharia; Revista Brasileira de Pesquisa em Educação em Ciência; Scientia Plena e Tecnologia e Sociedade.

Para o nosso estudo, fizemos abordagem semelhante utilizando as palavras "interdisciplinaridade" e "contextualização" no acervo do banco de dados citado. Não utilizamos a palavra CTS e suas derivações pelo fato do banco ter sido construído a partir destas palavras. Desta forma, obtivemos um total de 28 artigos (ver apêndice), que foram analisados quanto a diferentes aspectos: principais autores e trabalhos citados, autores e instituições que mais colaboraram com a temática, palavras-chave utilizadas e evolução da produção ao longo dos anos. Utilizamos a Análise de Redes Sociais para modelar autores produtores, instituições e palavras-chaves e, assim, observar se existe a presença de conexões entre os objetos analisados. Desta forma, é possível inferir a importância de cada componente na rede através de métricas derivadas das suas relações na rede.

Para a construção das redes e cálculo das métricas, foi utilizado o programa NodeXL, que funciona como um complemento do programa Excel (Microsoft). Este programa cria uma imagem estrutural das redes, para a verificação da existência de componentes conexos, que se relacionam ou não, possibilitando de maneira visual 
determinar componentes centrais. Também calcula diversas medidas de centralidade, porém, em nosso trabalho, optamos por utilizar apenas as centralidades de grau (determina quantas ligações tem um vértice, ou seja, a quantidade de citações, revelando o grau de prestígio na rede), de proximidade (o quanto um vértice é mais próximo do outro determina quais vértices podem chegar mais rapidamente a outros, ou seja, quem possui maior facilidade para acessar outro) e intermediação (mede a frequência com que um vértice está no menor caminho entre dois outros vértices, ou melhor, número de conexões entre diferentes sub-redes que um vértice é capaz de fazer, ou seja, a influência que este ator tem sobre os demais).

Para a elaboração da rede de palavras-chave adotamos duas decisões: 1) o termo CSTA que aparece em um dos artigos foi alterado para CTSA (Ciência, Tecnologia, Sociedade e Ambiente); 2) O termo Ciência, Tecnologia e Sociedade foi convertido na sigla CTS.

Para o estudo dos autores e artigos citados e anos de publicações, foram quantificadas suas entradas no Banco de Dados.

\section{ANÁLISES BIBLIOMÉTRICAS}

A partir de 244 artigos, foram selecionados 28 artigos resultantes da filtração pelas palavras temáticas, o que equivale a $11,48 \%$ do total de artigos da área de CTS voltada para o ensino de ciências, uma porcentagem, aparentemente, pequena, levando em consideração, principalmente, a importância da contextualização e da interdisciplinaridade na abordagem CTS. Verificamos o surgimento na produção brasileira em 2001; ano em que entrou em vigor o Plano Nacional de Educação (Lei no 10.172), o qual, em síntese, buscava a redução das desigualdades sociais e regionais com a elevação do nível de escolaridade da população e melhoria da 
qualidade do ensino em todos os níveis, procurando valorizar um paradigma curricular que possibilite a interdisciplinaridade. Nesse plano, a partir das concepções pedagógicas, embasadas na ciência da educação, é possível ver aspectos da reforma curricular expressa nos Parâmetros Curriculares Nacionais que, ao apresentar proposta de orientação aos professores, levantou a necessidade de os temas a serem trabalhados em cada área do conhecimento estarem vinculados ao cotidiano da maioria da população, configurando, assim, um ensino baseado na contextualização, uma vez que, conforme foi apresentado por Macedo e Silva (2014), a característica principal desse ensino é a possibilidade de aproximação e articulação dos conteúdos escolares com a realidade do estudante. O ano 2000 foi o primeiro ano de divulgação dos Parâmetros Curriculares Nacionais para o Ensino Médio (PCNEM), elaborado pelo Ministério da Educação (MEC), em um trabalho conjunto com educadores de todo o país, cujo objetivo era chegar a um novo perfil para o currículo, priorizando o ensino contextualizado e interdisciplinar e, portanto, pode ser atribuída a esse fato a publicação do primeiro artigo sobre contextualização e interdisciplinaridade dentro da abordagem CTS para o ensino de ciência. Em função disso, Strieder (2016), em seu estudo, investigou documentos oficiais como os PCNEM, identificando o respaldo que esse tipo de documento oferece à educação CTS.

Desde 2001 até 2015, ano onde ocorreu o auge de publicações com 5 artigos, a produção tem se mostrado pequena e irregular, com alguns anos sem nenhuma publicação, como é o caso dos anos 2003, 2004, 2005, 2008 e 2011, seguido no ano seguinte com um número substancial de trabalhos, conforme apresenta o Gráfico 1, possivelmente derivada de dissertações e teses. O número pequeno e irregular de publicações não se justifica levando em consideração que todos os periódicos em 
questão são publicados, em sua maioria, trimestral e quadrimestralmente. Apenas o periódico Ciência \& Ensino é publicado com periodicidade semestral. 
Gráfico 1: Publicações por ano. Fonte: Autores (2017).

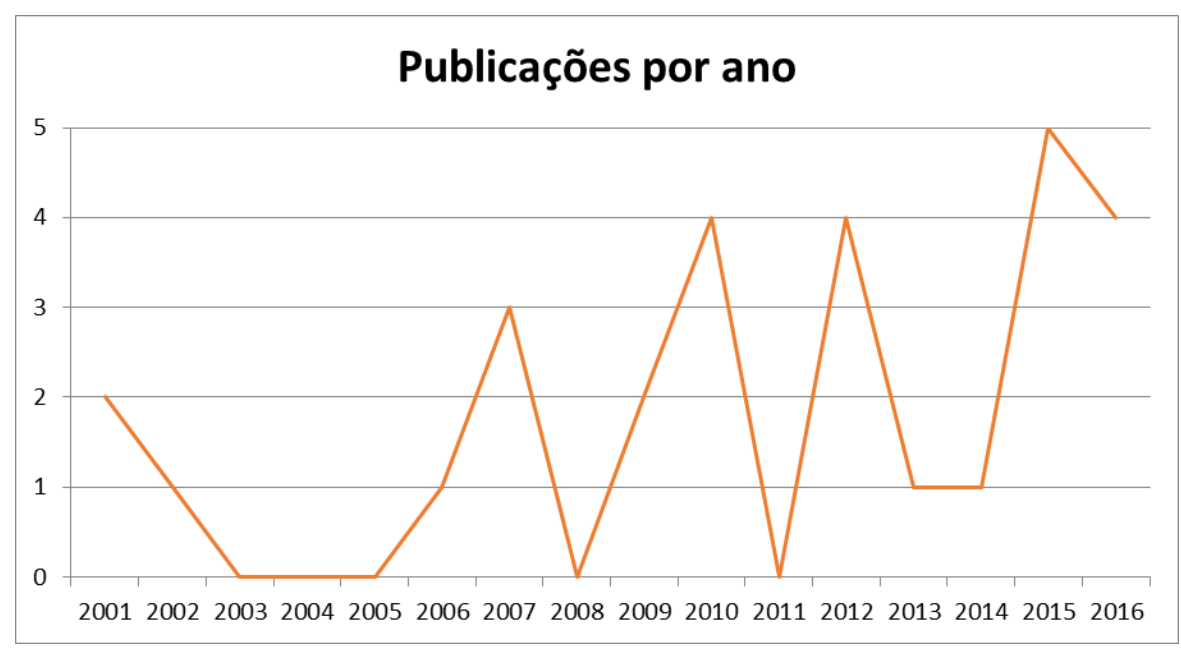

Ao compararmos o número de artigos constantes no Banco de Dados do Grupo CTS e Educação do CEFET/RJ, que tratam de contextualização e interdisciplinaridade no âmbito da abordagem CTS voltada para o ensino de ciências, publicados no período de 1996 a 2016, com o número de teses/dissertações que tratam dessas mesmas temáticas, publicadas nesse mesmo período, verificamos que o volume de teses/dissertações publicadas é consideravelmente maior do que o volume de artigos. No entanto, em termos proporcionais, ou seja, diante do volume total de artigos e de trabalhos stricto sensu publicados com o enfoque de CTS no ensino de ciências, o número de artigos que apresentam a contextualização e interdisciplinaridade na abordagem CTS é maior do que o número de teses/dissertações. Salienta-se que a pesquisa do volume de teses/dissertações publicadas no período informado foi realizada no site da Biblioteca Digital de Teses e Dissertações (BDTD), cujo editor é o Instituto Brasileiro de Informação em Ciência e Tecnologia (IBICT). Esse dado nos leva a inferir que a abordagem de CTS no ensino é de grande interesse para uma investigação mais aprofundada em um programa stricto sensu, porém, o estudo da contextualização e interdisciplinaridade no âmbito de tal abordagem é temática mais presente nos artigos científicos que, segundo Campello, Cendón e Kremer (2000), tem por objetivo a comunicação rápida e precisa 
sobre uma experiência ou observação específica, constituindo o meio mais importante para a comunicação da ciência.

A revista com maior número de publicações é a Revista Ciência \& Educação, da Universidade Estadual Paulista (UNESP), com 4 artigos. As revistas com o segundo maior número de publicações é a Química Nova na Escola, da Universidade de São Paulo (USP), a Revista Eletrônica Debates em Educação Científica e Tecnológica, do Instituto Federal do Espírito Santo (IFES) e a Revista Ensaio Pesquisa em Educação em Ciências, da Universidade Federal de Minas Gerais (UFMG), todas com 3 artigos.

Vale mencionar que a Revista Eletrônica Debates em Educação Científica e Tecnológica, do Instituto Federal do Espírito Santo (IFES), tem como editor-chefe Sidnei Quezada Meirelles Leites e é um dos autores que publica nas temáticas contextualização e interdisciplinaridade.

A instituição que mais publica artigos de interdisciplinaridade dentro da área CTS é a Universidade Federal de Santa Catarina (UFSC), totalizando 6 artigos. Em segundo lugar é o Instituto Federal do Espírito Santo (IFES) e em terceiro é a Universidade de Brasília (UnB) e a Universidade Tecnológica Federal do Paraná (UTFPR), com 3 artigos cada.

Os autores com maior número de artigos são, respectivamente, Sidnei Quezada Meireles Leite (4 publicações) e Manuella Villar Amado e Walter Antonio Bazzo, ambos com 3 publicações. Contudo, há de se considerar que o primeiro autor, conforme foi mencionado anteriormente, é o editor-chefe da Revista Eletrônica Debates em Educação Científica e Tecnológica, revista esta na qual o mesmo tem 2 artigos publicados sobre contextualização e interdisciplinaridade.

O Gráfico 1 apresenta os autores com maior produção, sendo possível verificar que somente 9 autores produziram 2 ou mais artigos no tema e no período avaliado. 
Gráfico 2: Artigos por autores. Fonte: Autores (2017).

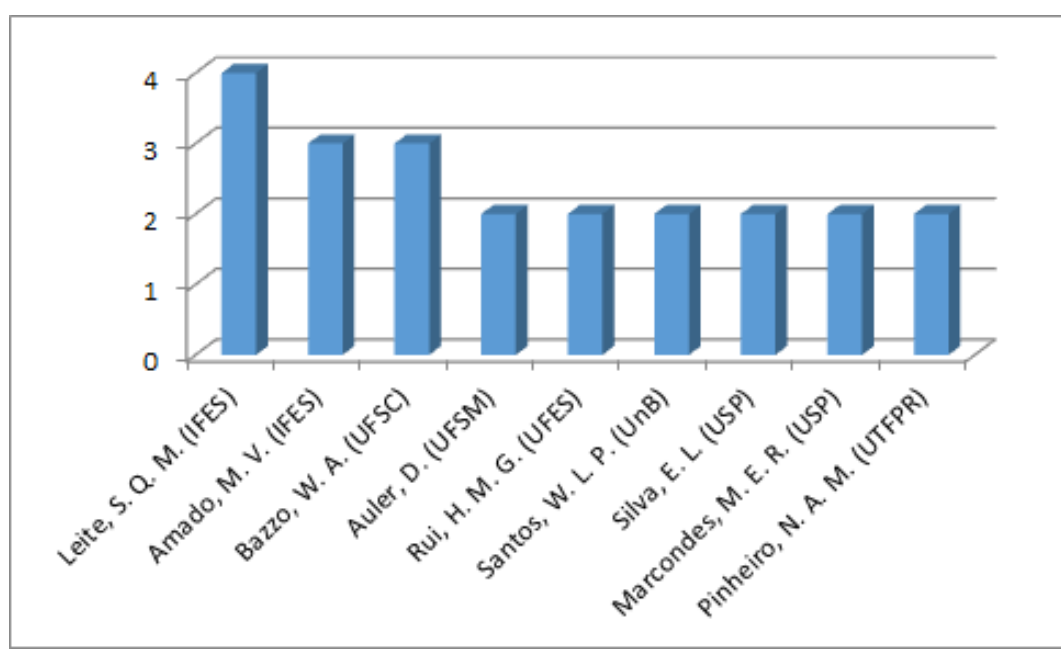

A área de formação dos autores é uma informação importante para análise, uma vez que nos permite saber quais áreas estão interessadas no estudo da interdisciplinaridade e contextualização em CTS. Assim dos 79 autores, 73 possuem mestrado e 64 possuem doutorado, enquanto . 14 dos 79 autores informam possuir estágios pós-doutorais. Vale informar que 13 dos 79 autores não possuem currículo disponível online e, portanto, não obtivemos informações quanto ao grau de instrução e a área de informação. Foi possível verificar que a maior parte dos autores possui graduação em Química, enquanto a área de Educação lidera nos níveis de mestrado, doutorado e pós-doutorado. O autor Sidnei Quezada Meireles Leite, identificado neste estudo como o autor que mais publica na área, tem formação em Química, enquanto Manuella Villar Amado e Walter Antonio Bazzo, são, respectivamente, das áreas de Biologia e Engenharia Mecânica.

Em relação às citações, de um total de 406 autores citados (foram analisados somente os primeiros autores), o autor mais citado foi Wildson Luiz Pereira dos Santos, com 49 citações, seguido das publicações do Ministério da Educação com 35, Décio Auler com 28, Paulo Freire com 19 e o restante conforme mostra a Tabela 1. Adotou-se como linha de corte os autores tiveram acima de 8 citações. 
Tabela 1: Autores mais citados. Fonte: Autores (2017).

\begin{tabular}{|c|c|}
\hline Autor & No de citações \\
\hline SANTOS, W. L. P & 49 \\
\hline BRASIL & 28 \\
\hline AULER, D. & 19 \\
\hline FREIRE, P. & 16 \\
\hline DELIZOICOV D. & 13 \\
\hline AIKENHEAD, G. S. & 13 \\
\hline KRASILCHIC, M. & 11 \\
\hline BAZZO, W. A. & 11 \\
\hline MOREIRA, M. A. & 10 \\
\hline SOLOMON, J. & 9 \\
\hline ACEVEDO DÍAZ, J. A. & 9 \\
\hline ANGOTTI, J. A. & \\
\hline
\end{tabular}

Das referências citadas, de um total de 599, a obra mais citada foi "Uma análise de pressupostos teóricos CTS (Ciência, Tecnologia e Sociedade) no contexto da educação brasileira", de Wildson Santos, com 15 citações, seguido de "BRASIL. Ministério da Educação - MEC, Secretaria de Educação Média e Tecnológica Semtec. Parâmetros Curriculares Nacionais para o Ensino Médio. Brasília: MEC/Semtec, 2000" com 11 citações, “Educação em química: compromisso com a cidadania', de Wildson Santos com 8 citações, "Pedagogia do oprimido", de Paulo Freire, com 7 citações, "BRASIL, Secretaria de Educação Média e Tecnológica. PCN+ Ensino Médio: orientações educacionais complementares aos Parâmetros Curriculares Nacionais. Ciências da Natureza, Matemática e suas Tecnologias" com 6 citações e "Ciência, tecnologia e sociedade: e o contexto da educação tecnológica", também com 6 citações. As demais tiveram de 5 a menos citações. 
O artigo mais citado de Wildson Santos, em coautoria com Mortimer, publicado em 2002, trata-se de um artigo de revisão, apresentando um panorama geral da área de CTS, identificando seus pressupostos teóricos no âmbito da educação brasileira. Apesar desse autor não ser o que mais publica voltado para as temáticas em questão neste estudo, devido ao caráter abrangente do artigo, mostrando as correntes teóricas da área de CTS e as discutindo criticamente, este artigo é também o mais citado na rede CTS-Brasil, desde as primeiras avaliações de redes CTS, feitas por Chrispino e colaboradores, em 2013.

A segunda referência mais citada não se trata de artigo, mas de uma publicação oficial, do MEC, que são os PCNEMs, publicada em 2000. Esse dado deixa clara a relação das publicações sobre as temáticas em questão na área de CTS com as diretrizes adotadas no novo currículo para o ensino médio que, até então, era baseado no ensino descontextualizado, compartimentalizado e baseado no acúmulo de informações.

O interessante é que, de todas as citações (599), apenas 149 foram em outra língua, sendo 83 delas em inglês, 59 em espanhol e 7 em francês, o que indica que os autores brasileiros recorrem pouco à literatura estrangeira, muito provavelmente por não terem o domínio de línguas estrangeiras, e isso pode ser um fato negativo para o desenvolvimento da área de CTS no Brasil, uma vez que os estudos na área em questão são mais desenvolvidos no âmbito internacional.

\section{ANÁLISES DE REDES SOCIAIS (ARS)}

Tendo como parâmetro o artigo de Chrispino Et al (2013), que cita as possibilidades oferecidas por uma rede social no campo de CTS, nesta seção apresentaremos tal abordagem, analisando os seguintes tipos de redes: coautoria, instituições e palavras-chave. 


\subsection{REDES DE COAUTORIA}

A rede de coautoria nos mostra como os autores estão interagindo entre si. A análise dos dados permite constatar que 3 autores não interagem com outros, aparecendo no grafo como círculos (Figura 1). Entretanto, Wildson Santos embora possua uma publicação como único autor, possui uma segunda em colaboração. Percebe-se ainda um sistema de coautoria em duplas, com a presença de 11 pares que não se relacionam com outros pesquisadores.

Figura 1: Redes de coautoria. Fonte: Autores (2017), gerado pelo NodeXL Basic

(http://nodexl.codeplex.com).

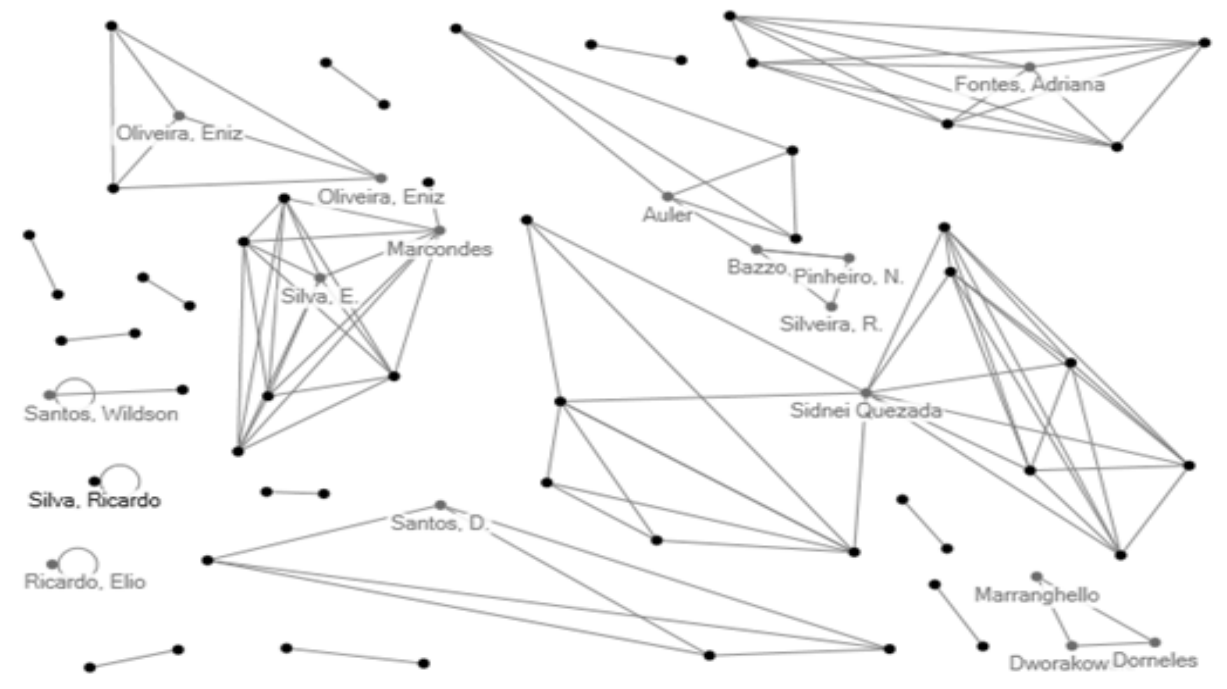

Existem 7 componentes conexos, porém só existem relacionamentos entre 4 componentes, 2 a 2, ou seja, existem apenas 2 redes. Nesta rede, Sidnei Quezada Meireles Leite é o autor central que interliga 2 grupos com 5 e 6 autores cada. Em seguida, os autores Manuela Vilar Amado, Décio Auler e Walter Antonio Bazzo constituem, respectivamente, autores centrais, porém interligam grupos com menor quantidade de autores que o primeiro autor mencionado. Vale observar que Manuela Vilar Amado é a segunda autora com um maior número de colaborações, em um total de 8 colaborações, atrás apenas de Sidnei Quezada Meireles Leite, com 
9 colaborações. Embora existam dois grupos com quatro autores cada, nenhum deles aparece como central, e de todos os vértices saem números iguais de arestas. Os demais autores não são centrais, ou seja, não interligam componentes conexas.

Na Tabela 2 estão listadas as medidas de centralidade de grau, intermediação e proximidade para os autores mais destacados na análise. Sobre tais medidas de centralidade e visando introduzir tal conceito, Chrispino Et al. (2013, p. 460) apresentam a definição abaixo:

As medidas de centralidade posicionam os pontos da rede a partir de graus que indicam as posições mais centrais na malha da rede, de acordo com a finalidade da abordagem. Existem diferentes tipos de centralidade nas redes sociais, e, em algumas delas, não são os pontos com mais ligações diretas que ocupam posições mais centrais, mas aqueles que, por sua posição estratégica, têm papel de destaque na informação e comunicação.

A centralidade de grau (degree centrality) é uma medida que indica quantas ligações tem um vértice, ou seja, os graus de entrada e saída de um vértice (CHRISPINO Et al., 2013). A partir das considerações apresentadas por Freeman (1979) e Marteleto (2001) é possível definir que a centralidade de proximidade (closeness centrality) mede quais os vértices está em menor distância dos outros vértices que fazem parte da rede, enquanto a centralidade de intermediação (betweenness centrality) mede o quanto um determinado vértice é importante no fluxo de informação, atuando como facilitador nesse processo. Deste modo, foram enumerados apenas aqueles com medidas de centralidade de intermediação diferentes de zero, por entendermos que são estes os atores responsáveis pelo fluxo da informação, mesmo que muitos autores tiveram medidas de centralidade de grau altas. 
Tabela 2: Medidas de centralidade calculadas para autores com centralidade de intermediação diferente de zero. Fonte: Autores (2017).

\begin{tabular}{|c|c|c|c|}
\hline Autor & Centralidade de grau & $\begin{array}{c}\text { Centralidade de } \\
\text { intermediação }\end{array}$ & $\begin{array}{c}\text { Centralidade de } \\
\text { proximidade }\end{array}$ \\
\hline $\begin{array}{c}\text { Sidnei Quezada } \\
\text { Meireles Leite }\end{array}$ & 9 & 13 & 0,111 \\
\hline Manuela Villar Amado & 8 & 5 & 0,100 \\
\hline Décio Auler & 4 & 9 & 0,125 \\
\hline Walter Antonio Bazzo & 3 & 8 & 0,111 \\
\hline
\end{tabular}

O autor Sidnei Quezada Meireles Leite foi o que apresentou maior centralidade de grau e de intermediação, conforme já tinha sido identificado na Figura 1.

\subsection{REDES DE INSTITUIÇÕES}

Ao analisarmos a rede, verificou-se que das 20 instituições, 8 não se relacionam com nenhuma outra. As 5 instituições que se relacionam com mais de uma instituição são, respectivamente: UFSC (4 colaborações), IFES (3 colaborações), UTFPR (3 colaborações), UFSM (2 colaborações) e UFBA (2 colaborações). Existem apenas 2 componentes conexos, sendo a UFSC a única instituição central. Esse dado revela que as instituições interagem muito pouco entre si, trabalhando, a maior parte delas, de forma isolada. Esta tendência talvez possa explicar o pequeno número de publicações no tema, sugerindo não tratar-se de linhas de pesquisa, mas sim trabalhos esporádicos realizados tão somente para um determinado fim. 
Tabela 3: Medidas de centralidade calculadas para instituições. Fonte: Autores (2017).

\begin{tabular}{|c|c|c|c|}
\hline Instituição & Centralidade de grau & $\begin{array}{c}\text { Centralidade de } \\
\text { intermediação }\end{array}$ & $\begin{array}{c}\text { Centralidade de } \\
\text { proximidade }\end{array}$ \\
\hline UFSC & 5 & 4,0 & 0,2 \\
\hline UnB & 3 & 0,0 & 1,0 \\
\hline UNICSUL & 3 & 0,0 & 1,0 \\
\hline UTFPR & 2 & 3,0 & 0,167 \\
\hline IFES & 2 & 0,0 & 0,5 \\
\hline
\end{tabular}

Em razão da UFSC ser a instituição que mais colabora com outras, seu grau de centralidade é maior em relação às demais instituições, conforme apresentado na Tabela 3, atuando como um facilitador no fluxo de informações da rede e, portanto, apresentando uma centralidade de intermediação também maior. As instituições UnB, UNICSUL e IFES não apresentam nenhuma intermediação.

\subsection{Redes de PalaVRas-Chave}

Foram identificadas 58 palavras-chave citadas nos artigos. A partir delas, foi delimitada a rede da Figura 3, que mostra que as palavras chaves que mais aparecem nos artigos e, portanto, com maior grau de centralidade, são: CTS (grau de centralidade: 18), interdisciplinaridade (grau de centralidade: 18), ensino de ciências (grau de centralidade: 11), ensino e aprendizagem (grau de centralidade: 9), CTSA (grau de centralidade: 8) e contextualização (grau de centralidade: 7). Uma vez que o banco foi criado a partir da palavra-chave CTS, esta teve a maior centralidade de intermediação $(723,83)$, enquanto interdisciplinaridade ficou em segundo lugar com 635,66 e ensino de ciências em terceiro com 388, seguido de contextualização com 201,5. A Tabela 4 mostra as palavras-chave e suas respectivas medidas de centralidade de grau, de intermediação e de proximidade. Adotaram-se como linha de corte as palavras-chave que obtiveram grau de centralidade superior a 4. 
Tabela 4: Medidas de centralidade calculadas para palavras-chave. Fonte: Autores (2017).

\begin{tabular}{|c|c|c|c|}
\hline Palavra-Chave & $\begin{array}{c}\text { Centralidade de } \\
\text { Grau }\end{array}$ & $\begin{array}{c}\text { Centralidade de } \\
\text { intermediação }\end{array}$ & $\begin{array}{c}\text { Centralidade de } \\
\text { proximidade }\end{array}$ \\
\hline Interdisciplinaridade & 18 & 635666667,000 & 0,009 \\
\hline CTS & 18 & 723833333,000 & 0,009 \\
\hline Ensino de ciência & 11 & 388,000 & 0,008 \\
\hline Ensino e aprendizagem & 9 & 185,500 & 0,008 \\
\hline CTSA & 8 & 343,333 & 0,007 \\
\hline Contextualização & 7 & 201,500 & 0,006 \\
\hline Alfabetização científica e & 6 & & 0,007 \\
tecnológica & & 14,333 & \\
\hline Abordagem cts & 5 & & 0,005 \\
\hline Ensino médio & 5 & 102,333 & 0,007 \\
\hline
\end{tabular}

Um dado a ser destacado e que merece atenção é o fato das palavras-chave interdisciplinaridade e CTS apresentarem o mesmo grau de centralidade, o que mostra o quão importante é a questão da interdisciplinaridade nos estudos CTS, conforme apresentado na introdução deste trabalho, uma vez que interdisciplinaridade é inerente à área de CTS. 
Figura 2: Redes de palavras-chave. Fonte: Autores (2017), gerado pelo NodeXL Basic (http://nodexl.codeplex.com).

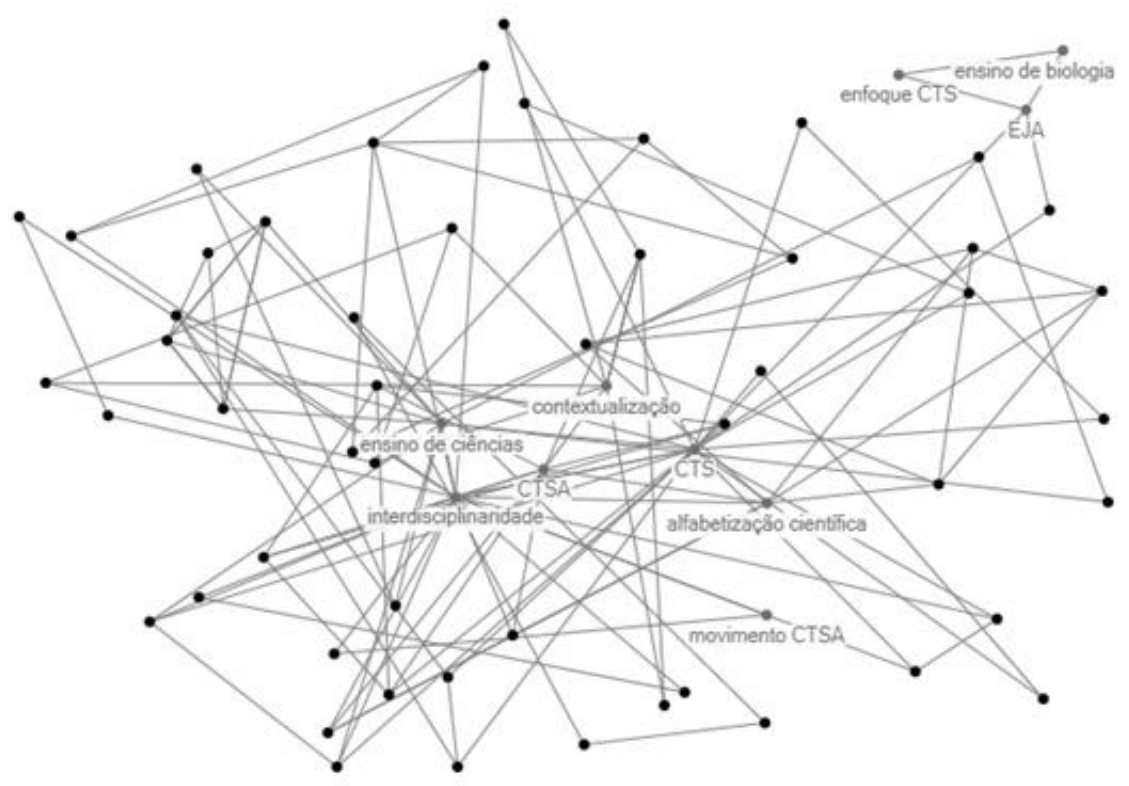

Com base nos dados apresentados, verificamos que a temática interdisciplinaridade é mais abordada nos estudos CTS do que a temática contextualização, muito embora alguns autores as considerassem como sinônimo uma da outra, o que, no capítulo de revisão de literatura deste trabalho, foi mostrado que não procede, tendo cada conceito a sua especificidade.

As palavras-chave "ensino de ciências" e "alfabetização científica" tem clara relação com a interdisciplinaridade e contextualização, uma vez que, de acordo com as orientações curriculares para o ensino médio em relação às ciências da natureza e matemática, tem como base um ensino contextualizado e interdisciplinar (BRASIL, 2006), o que facilita no conhecimento e entendimento dos conceitos científicos.

\section{ANÁLISE DE ARTIGOS}

Os artigos selecionados foram analisados com vistas a um exame pormenorizado e crítico. Dessa maneira, constatou-se que o tema interdisciplinaridade geralmente não é debatido nas publicações, sendo tão somente 
sugeridos. Assim, a maioria dos trabalhos versa sobre a aplicação da interdisciplinaridade em termos práticos, deixando a teoria sobre o assunto de lado. Esta aplicação é, em sua maioria realizada no ensino médio, através de sequências didáticas que envolvem pesquisa sobre um determinado tema, seguido por júri simulado ou experimentos.

$\mathrm{Na}$ análise dos artigos identificou-se 3 (três) categorias de abordagem que mais se destacaram, são elas: ensino de química, ensino de física e educação CTSA. Os professores de química mostraram-se mais dedicados a esta prática de ensino, seguido pelos professores de física. A abordagem de CTS no ensino de química é feita por meio de proposta de sequência didática, inclusive no contexto da Educação de Jovens e Adultos (EJA) (FERREIRA; VASCONCELOS, 2016), de análise das questões do Exame Nacional do Ensino Médio (ENEM), identificando possíveis compreensões da noção de contextualização presentes (FERNANDES; MARQUES, 2015), de formação continuada de professores de química e de elaboração de materiais didáticos/instrucionais (MARCONDES Et al., 2009 e SILVA; MARCONDES, 2010). No ensino de física, a abordagem CTS é feita de maneira similar, incluindo análise de livros didáticos aprovados pelo PNLEM (MACEDO; SILVA, 2010), abordagem voltada para o ensino médio profissionalizante (ARAÚJO; FORMENTON, 2012) e a abordagem de um currículo temático baseado em pressupostos freireanos, dentro da perspectiva CTS, por professores de física em formação inicial, na tentativa de enfrentar desafios na educação, como a evasão escolar (ROSO Et al., 2015).

Predominaram os temas ambientais, através de uma abordagem CTS no ensino, o que resulta na educação CTSA. Os artigos que tratam desse tema abordam a interdisciplinaridade na pedagogia de projetos (REZENDE Et al., 2014), as questões que constituem verdadeiros obstáculos para a educação CTSA e as possibilidades para sua implementação no contexto escolar (RICARDO, 2007), os materiais 
instrucionais na perspectiva CTSA (MARCONDES Et al, 2009), o ensino por pesquisa de núcleos integrados no contexto do ensino médio (RIBEIRO, GENOVESE, 2015) e o ensino de genética no ensino fundamental por meio de sequência didática (LENOR et al., 2012).

Em geral, quando abordavam explicitamente o tema interdisciplinaridade, houve o consenso no sentido de que este enunciado não significa apenas uma justaposição de matérias, senão a cooperação entre as áreas de conhecimento. Esta cooperação não deve ser implementada por um professor polivalente, mas sim com a colaboração integrada dos docentes de diferentes áreas do conhecimento. 0 importante é que todas as áreas sejam fortalecidas ao final. Por outro lado, contextualização é vista apenas como uma delimitação de matéria. Alguns eram artigos de discussão e reflexão sobre o assunto, não sendo, portanto, aplicada a um público específico ou utilizada alguma metodologia.

\section{CONCLUSÃO OU CONSIDERAÇÕES FINAIS}

As considerações a serem apresentadas só devem ser tidas como finais no âmbito deste artigo, na medida em que lhe dão o fecho necessário e obrigatório. Contudo, para o propósito de explorar a produção científica sobre interdisciplinaridade e contextualização com enfoque em CTS e voltada para o ensino de ciências, tais considerações devem ser vistas como iniciais, podendo suscitar outras reflexões que venham contribuir para o desenvolvimento da abordagem CTS como um campo do conhecimento que ainda está em expansão.

Voltando para a pergunta inicial norteadora deste trabalho "como a interdisciplinaridade e contextualização se apresentam no âmbito da abordagem CTS", com base nos resultados preliminares, é possível verificar que é pouco expressiva a quantidade de artigos que abordam tais temáticas voltadas para o 
estudo de CTS no ensino de ciências, consistindo em aproximadamente 11,5\% da produção científica que faz parte do CTS Brasil. Por meio da análise bibliométrica dos artigos selecionados e de acordo com as categorias discriminadas, constatou-se que: os primeiros artigos que aproximam o tema da interdisciplinaridade da área de CTS datam de 2001; o ano de 2015 foi o ano com maior publicação de artigos voltados para essa abordagem; dentre as referências citadas, há predominância de fontes nacionais e apenas 149 consiste em trabalhos publicados em outros idiomas, tais como espanhol, francês e inglês, concentrando a maioria neste último; a revista com maior publicação de artigos é a Revista Ciência \& Educação, publicada pela UNESP; a instituição que mais publica é a UFSC; o autor que mais publica sobre as temáticas contextualização e interdisciplinaridade na área de CTS, Sidnei Quezada Meireles Leite, não é o mais citado que, de acordo com os dados levantados neste estudo, o autor com o maior número de citações é o Wildson Santos, da UnB, o qual, não por coincidência, é o mais citado na Rede CTS-Brasil; a maior parte dos autores que publicam na área possui mestrado e doutorado; a maioria dos autores tem formação na área Química (Graduação) e na área de Educação (Doutorado).

Por meio da análise de redes sociais e de acordo com as categorias estabelecidas, os resultados apresentados permitem inferir que: os autores que publicam na área fazem parte de grupos segregados, levando em consideração o contexto geral, pois, em sua maioria, não apresentam interação com outros grupos; as instituições não apresentam boa interação entre elas, sendo 8 delas instituições que trabalham isoladamente e apenas 6 se relacionam com, no mínimo, 2 instituições e, no máximo, 3 instituições, sendo a UFSC a que mais se relaciona o que pode ser explicado pela existência de programa de pós-graduação consolidado, levando a publicação de aluno e orientador, tema que pode ser explorado futuramente, sendo esta a instituição que mais publica; as palavras-chave com maior 
número de vértices são: CTS, interdisciplinaridade, ensino de ciências, contextualização, alfabetização científica e contextualização; a palavra-chave CTS teve a maior centralidade de intermediação e a interdisciplinaridade ficou em segundo lugar.

Por meio das leituras dos artigos selecionados, verifica-se que a palavra contexto, presente nos artigos selecionados, muitas vezes é usada apenas como uma palavra com a função de indicar partes de um todo, apresentando delimitação geográfica ou de abordagem, e não no sentido de apresentar o conceito contextualização como sendo extremamente significativo nos estudos CTS. A ideia de contextualização significar partes de um todo, por ser uma derivação do termo contexto, é expressa em Kato (2007), mencionada na seção 1.2 deste trabalho. Verificou-se também que as palavras "contextualização" e "interdisciplinaridade" aparecem neles, na maioria das vezes, sem sua devida conceituação, mas, sobretudo, por se tratarem de características da abordagem CTS, onde o contexto é apresentado pelos autores como o elemento facilitador no processo de ensino e aprendizagem e a prática interdisciplinar consiste em uma prática pedagógica ampla e que reconhece a necessidade de rompimento das barreiras existentes entre as disciplinas, na tentativa de lançar uma ponte para ligar essas fronteiras que haviam sido estabelecidas, conforme mencionado na frase de Japiassú (1976) escolhida para a abertura deste artigo. Porém, na maioria das vezes, o tema interdisciplinaridade não é debatido, sendo apenas sugerido, desconsiderando a teoria sobre o assunto, predominando, portanto, artigos que versam unicamente sobre a aplicação da interdisciplinaridade em termos práticos. 


\section{REFERÊNCIAS}

ACEVEDO, J.A., VAZQUEZ, A. y MANASSERO, M. A. El Movimiento Ciencia-TecnologíaSociedad y la Enseñanza de las Ciencias [que reproduz Manassero, Ma A, Vasquez, A. y Acevedo, J.A. Avaluació dels temes de ciència, tecnologia i societat. Palma de Mallorca (España): Conselleria d’Educació i Cultura del Govern de les Illes Ballears, 2001. Disponível em: http://www.oei.es/salactsi/acevedo13.htm. Acesso em 14 ago. 2017

BARNES, J. A. Class and Committee in a Norwegian Island Parish, Human Relations, v. 7, n. 1, p. 39-58, 1954.

BAZZO, W. A.; LINSINGEN, I. von e PEREIRA, L. T. do V. Introdução aos Estudos CTS (Ciência, Tecnologia e Sociedade). Cadernos de Ibero América. OEl-Organização dos Estados Iberoamericanos para a Educação, a Ciência e a Cultura. Espanha: Madrid, 2003.

BRASIL. Lei de Diretrizes e Bases da Educação Nacional, Lei n 9.394, de 20 dez. 1996. BRASIL. Ministério da Educação. Secretaria de Educação Média e Tecnológica. Parâmetros curriculares nacionais: ensino médio. Brasília: MEC/SEMTEC, 1999. 4v. BRASIL. Ministério da Educação. Secretaria de Educação Básica. Orientações curriculares para o ensino médio: ciências da natureza, matemática e suas tecnologias. Brasília : MEC/SEB, 2006. v.2

CACHAPUZ, A. Et al. (Orgs.). A necessária renovação do ensino de ciências. São Paulo: Cortez, 2005.

CAMPELLO, B. S.; CENDÓN, B. V.; KREMER, J. M. (Org.). Fontes de informação para pesquisadores e profissionais. Belo Horizonte: UFMG, 2000. 
CHRISPINO, A. Introdução aos enfoques CTS - Ciência, Tecnologia e Sociedade - Na educação e no ensino. 1. ed. Brasília, DF : Ed. OEl-Organização dos Estados Iberoamericanos, 2017.

CHRISPINO, A. O enfoque CTS - Ciência, Tecnologia e Sociedade e seus impactos no ensino. Revista Tecnologia \& Cultura. Rio de Janeiro, ano 10, n. 13, p. 7-17, jul./dez. 2008.

CHRISPINO, A. Et al. A área CTS no Brasil vista como rede social: onde aprendemos? Ciência \& Educação, v. 19, p. 455-479, 2013. Disponível em:

<http://www.scielo.br/pdf/ciedu/v19n2/a15v19n2.pdf>. Acesso em: 22 jun. 2017.

CUTCLIFFE, S. H. Ideas, máquinas y valores. Los estudios de Ciencia, Tecnología y Sociedad. Barcelina: Anthropos; México: UNAM, 2003.

FAZENDA, I. C. A. Interdisciplinaridade-transdisciplinaridade: visões culturais e epistemológicas. O que é interdisciplinaridade, p. 17-28, 2008.

FAZENDA, Ivani Catarina Arantes. Virtude da força nas práticas interdisciplinares. Papirus Editora, 1999.

FORQUIN, J.-C. Curriculum: between relativism and universalism. Educação \& Sociedade, v. 21, n. 73, p. 47-70, 2000.

FREEMAN, L. C. Centrality in social networks: Conceptual clarification. Social Networks, v. 1, n. 3, 215-239, 1979. Disponível em: < http://citeseerx.ist.psu.edu/viewdoc/download?doi=10.1.1.320.5551\&rep=rep1\&typ e=pdf $>$. Acesso em 24 jun. 2017.

JAPIASSÚ, H. Interdisciplinaridade e patologia do saber. Rio de Janeiro: Imago, 1976. JAPIASSÚ, H. O sonho transdisciplinar: e as razões da filosofia. 2006. 
KATO, D. S. O significado pedagógico da contextualização para o ensino de ciências: análise dos documentos curriculares oficiais e de professores. 2007. $119 f$. Dissertação (mestrado - Programa de Pós-Graduação em Educação, área de concentração: Ensino de Ciências e Matemática) - Faculdade de Educação da Universidade de São Paulo.

LOPES, A. C. Os parâmetros curriculares nacionais para o ensino médio e a submissão ao mundo produtivo: o caso do conceito de contextualização. Educ. Soc., Campinas, v.23, n.80, p. 386-400, set./2002.

MACEDO, C. C.; SILVA, L. F. Os processos de contextualização e a formação inicial de professores de física. Investigações em Ensino de Ciências, v. 19, n. 1, p. 55-75, 2015. MARTELETO, R. M. Análise de redes sociais: aplicação nos estudos de transferência da informação. Ciência da Informação, Brasília, v. 30, n. 1, p. 71-81, 2001.

MEMBIELA, P. Una revisión del movimiento CTS en la enseñanza de las ciencias. In: MEMBIELA, P. (ed.). Enseñanza de las ciencias desde la perspectiva cienciatecnología-sociedad: formación científica para la ciudadanía. Madrid: Narcea, 2001. p. 91-103.

POMBO, O.; GUIMARÄES, H. M.; LEVY, T. A interdisciplinaridade: reflexão e experiência. 1993.

POMBO, O. A Escola, a recta e o círculo. Lisboa: Relógio d’Água, 2002.

ROCHA, M. L. Et al. Representatividade da biologia em CTS por meio de análise por redes sociais. Contexto \& Educação, ljuí, RS, ano 32, n. 102, p. 81-99, maio/ago.2017. RUI, H. M. G. et al. "Uma prova de amor: o uso do cinema como proposta pedagógica para contextualizar o ensino de genética no ensino fundamental." Revista Brasileira de Ensino de Ciência e Tecnologia 6.2 (2013). 
SANTOS, W. L. P. (2007). Contextualização no ensino de ciências por meio de temas CTS em uma perspectiva crítica. Ciência \& Ensino, v. 1, número especial, novembro de 2007.

SAREWITZ, D. Frontiers of illusion: science, technology and problems of progress. Philadelphia: Temple University Press, USA, 1996.

STRIEDER, R. B. Et al. A educação CTS possui respaldo em documentos oficiais brasileiros? ACTIO, Curitiba, v. 1, n. 1, p. 87-107, jul./dez. 2016. Disponível em: < https://periodicos.utfpr.edu.br/actio/article/view/4795>. Acesso em 21 jun. 2017. TEIXEIRA, P. M. M. Educação científica e movimento CTS no quadro das tendências pedagógicas no Brasil. Revista Brasileira de Pesquisa em Educação em Ciências, Belo Horizonte, v. 3, n. 1, p.88-102, 2003.

TRÓPIA, G.; AMORIM, F.; MARTINS, M. C.. Aproximações sobre a organização do conhecimento científico nas propostas pedagógicas baseadas em Paulo Freire e CTS no ensino de ciências. Revista Tecnologia \& Cultura, Rio de Janeiro, ano 10, n. 13, p. 37-45, jul./dez. 2008. 


\section{APÊNDICE 1 - ARTIGOS SELECIONADOS}

\begin{tabular}{|c|c|}
\hline 1 & $\begin{array}{l}\text { AMS, F. W. et al. Contribuições de aulas contextualizadas para a formação } \\
\text { tico/reflexiva de alunos da educação básica. REnCiMa, v.7, n.3, p. 01-17, } 2016 \text {. }\end{array}$ \\
\hline 2 & $\begin{array}{l}\text { JGOTTI, J. A. P.; AUTH, M. A. Ciência e Tecnologia: Implicações Sociais e o Papel da } \\
\text { ucação. Ciência \& Educação, v.7, n.1, p.15-27, } 2001 \text {. }\end{array}$ \\
\hline 3 & $\begin{array}{l}\text { RAÚJO, M. S. T.; FORMENTON, R. Fontes Alternativas de Energia Automotiva no Ensino } \\
\text { lédio Profissionalizante análise de uma proposta contextualizada de ensino de física em } \\
\text { m curso técnico. ALEXANDRIA Revista de Educação em Ciência e Tecnologia, v.5, n.1, } \\
\text { 33-61, maio 2012. }\end{array}$ \\
\hline 4 & $\begin{array}{l}\text { LER, D.; BAZZO, W. A. Reflexões para a implementação do movimento CTS no contexto } \\
\text { ucacional Brasileiro. Ciência \& Educação, v.7, n.1, p.1-13, } 2001 .\end{array}$ \\
\hline 5 & $\begin{array}{l}\text { CUSSI, A. A.; OSTERMANN, F. Projetos curriculares interdisciplinares e a temática da } \\
\text { ergia. Experiências em Ensino de Ciências, v.1, n.1, p. 01-13, } 2006 .\end{array}$ \\
\hline 6 & $\begin{array}{l}\text { DIESEL, A. Contribuições da língua portuguesa para uma proposta de letramento científico } \\
\text { e tecnológico no contexto escolar. Revista Eletrônica Debates em Educação Científica e } \\
\text { Tecnológica, v. 6, n. 2, p. } 58 \text { - 69, jun. } 2016 \text {. }\end{array}$ \\
\hline 7 & $\begin{array}{l}\text { P. F. T. O aquecedor solar na } \\
\text { 147-162, } 2010 .\end{array}$ \\
\hline 8 & interdisciplinar no ensino \\
\hline 9 & $\begin{array}{l}\text { FERREIRA, K. M.; VASCONCELOS, T. N. H. O efeito de uma sequência didática de cálculos } \\
\text { químicos com enfoque CTS no contexto da EJA. R. Tecnol. Soc., Curitiba, v. 12, n. 24, p. 1- } \\
\text { 26, jan./abr. } 2016 \text {. }\end{array}$ \\
\hline 10 & $\begin{array}{l}\text { FERNANDES, C. S.; MARQUES, C. A. Noções de Contextualização nas Questões } \\
\text { Relacionadas ao Conhecimento Químico no Exame Nacional do Ensino Médio. Química } \\
\text { Nova na Escola, v. 37, n. 4, p. 294-304, NOVEMBRO } 2015 .\end{array}$ \\
\hline 11 & $\begin{array}{l}\text { JGER, J. G.; Leite, S. Q. M. Jornal da ciência como atividade interdisciplinar extraclasse: } \\
\text { ates e reflexões sobre a ciência na comunidade escolar de ensino médio. In: Anais do } \\
\text { ncontro Nacional de Ensino de Ciências da Saúde e do Ambiente. Niterói (RJ). } 2012 .\end{array}$ \\
\hline 12 & $\begin{array}{l}\text { NOR, P. B. et al. Revolução genômica: uma sequência didática para contextualizar o } \\
\text { ino de genética no ensino fundamental dentro de uma perspectiva CTSA. Revista } \\
\text { rônica Debates em Educação Científica e Tecnológica, v. 2, n.02, p. 68-80, dez. } 2012\end{array}$ \\
\hline 13 & $\begin{array}{l}\text { RRCONDES, M. E. R. et al. Materiais instrucionais numa perspectiva CTSA-uma análise } \\
\text { unidades didáticas produzidas por professores de química em formação continuada. } \\
\text { estigações em Ensino de Ciências, v. 14, n. 2, p. 281-298, } 2009 \text {. }\end{array}$ \\
\hline 14 & $\begin{array}{l}\text { MACEDO, C. C.; SILVA, L. F. Contextualização e visões de ciência e tecnologia nos livros } \\
\text { didáticos de física aprovados pelo PNLEM. ALEXANDRIA Revista de Educação em Ciência e } \\
\text { Tecnologia, v.3, n.3, p.1-23, nov. } 2010 \text {. }\end{array}$ \\
\hline 15 & $\begin{array}{l}\text { PORTO, M. L. O.; TEIXEIRA, P. M. M. A articulação da tríade CTS: reflexões sobre o } \\
\text { desenvolvimento de uma proposta didática aplicada no contexto da EJA. Investigações em } \\
\text { Ensino de Ciências, v.21, n. 1, p. 124-144, } 2016 \text {. }\end{array}$ \\
\hline 16 & $\begin{array}{l}\text { PINHEIRO, N. A. M.; BAZZO, W. A. Caso simulado no Ensino-aprendizagem de matemática: } \\
\text { ensinar sob uma abordagem crítica. Bolema, Rio Claro (SP), Ano 22, no 32, 2009, p. } 101 \text { a } \\
\text { 122. }\end{array}$ \\
\hline
\end{tabular}




\begin{tabular}{|c|c|}
\hline 17 & $\begin{array}{l}\text { NHEIRO, N. A. M.; SILVEIRA, R. M. C. F.; BAZZO, W. A. Ciência, tecnologia e sociedade-a } \\
\text { levância do enfoque CTS para o contexto do ensino médio. Ciência \& Educação, v. 13, n. } \\
\text { p. 71-84, } 2007 \text {. }\end{array}$ \\
\hline 18 & $\begin{array}{l}\text { CARDO, E. C. Educação CTSA: Obstáculos e possibilidades para sua implementação no } \\
\text { ntexto escolar. Ciência \& Ensino, v. 1, número especial, novembro de } 2007\end{array}$ \\
\hline 19 & $\begin{array}{l}\text { ROEHRIG, S. A. G.; CAMARGO, S. A educação com enfoque CTS no quadro das tendências } \\
\text { de pesquisa em ensino de ciências algumas reflexões sobre o contexto brasileiro atual. In: } \\
\text { Anais do III Simpósio Nacional de Ensino de Ciência e Tecnologia, Ponta Grossa-PR, } 26 \text { a } 28 \\
\text { de } 2012 \text {. }\end{array}$ \\
\hline 20 & $\begin{array}{l}\text { REZENDE, B. L. A. et al. A interdisciplinaridade por meio da pedagogia de projetos: uma } \\
\text { análise do projeto "Horta escolar: aprenda cultivando hortaliças" numa perspectiva CTSA. } \\
\text { Revista Eletrônica Debates em Educação Científica e Tecnológica, v. 04, n. 01, p. } 52 \text { - 51, } \\
\text { Jun. } 2014\end{array}$ \\
\hline 21 & $\begin{array}{l}\text { ROSO, C. C. et al. Currículo temático fundamentado em Freire-CTS: engajamento de } \\
\text { professores de física em formação inicial. Revista Ensaio, Belo Horizonte, v.17, n. 2, p. } \\
\text { 372-389, maio/ago. } 2015 \text {. }\end{array}$ \\
\hline 22 & $\begin{array}{l}\text { RIBEIRO, T. V.; GENOVESE, L. G. R. O emergir da perspectiva de Ensino por Pesquisa de } \\
\text { Núcleos Integrados no contexto da implementação de uma proposta CTSA no Ensino } \\
\text { Médio. Ciênc. Educ., Bauru, v. } 21, \text { n. } 1 \text {, p. 1-29, } 2015 \text {. }\end{array}$ \\
\hline 23 & $\begin{array}{l}\text { RUI, H. M. G. et al. Uma prova de amor: o uso do cinema como } \\
\text { contextualizar o ensino de genética no ensino fundamental. R. E } \\
\text { 6, n. 2, mai./ago. } 2013 \text {. }\end{array}$ \\
\hline 24 & $\begin{array}{l}\text { SILVA, R. R.; GOMES, V. B. A Seção Química e Sociedade: C } \\
\text { em Diferentes Contextos. Química Nova na Escola, v. 37, n } \\
2015 .\end{array}$ \\
\hline 25 & $\begin{array}{l}\text { SILVA. R. O. Cana de Mel, Sabor de Fel-Capitania de Pernambuco: Uma Int } \\
\text { Pedagógica com Caráter Multi e Interdisciplinar. Química Nova na Escola, v. 32, n } \\
\text { 94, maio 2010. }\end{array}$ \\
\hline 26 & $\begin{array}{l}\text { SANTOS, W. L. P. Contextualização no Ensino de Ciências por meio de temas CTS em uma } \\
\text { perspectiva crítica. Ciência \& Ensino, v. 1, número especial, novembro de } 2007 .\end{array}$ \\
\hline 27 & $\begin{array}{l}\text { SANTOS, W. L. P.; MORTIMER, E. F. Uma análise de pressupostos teóricos da abordagem } \\
\text { C-T-S (Ciência-Tecnologia-Sociedade) no contexto da educação brasileira. Rev. Ensaio, } \\
\text { Belo Horizonte, v.02, n.02, p.110-132, jul./dez. } 2000 \text {. }\end{array}$ \\
\hline 28 & $\begin{array}{l}\text { SILVA, E. L.; MARCONDES, M. E. R. Visões de Contextualização de Professores de Química } \\
\text { na Elaboração de seus próprios materiais didáticos. Rev. Ensaio, Belo Horizonte, v.12, } \\
\text { n.01, p.101-118, jan./abr. } 2010 \text {. }\end{array}$ \\
\hline
\end{tabular}

Recebido em: Dezembro de 2017. Publicado em: Abril de 2018. 